\title{
Candida parapsilosis Colony Morphotype Forecasts Biofilm Formation of Clinical Isolates
}

\author{
Emilia Gómez-Molero ${ }^{1,2}$, Iker De-la-Pinta ${ }^{3}$, Jordan Fernández-Pereira ${ }^{2}$, Uwe Groß ${ }^{1}$, Michael Weig ${ }^{1}$, \\ Guillermo Quindós ${ }^{3}$ (D) Piet W. J. de Groot ${ }^{2, *(\mathbb{D})}$ and Oliver Bader $1, *$ (D) \\ 1 Institute for Medical Microbiology, University Medical Center Göttingen, Kreuzbergring 57, \\ 37075 Göttingen, Germany; emiliagomez803@hotmail.com (E.G.-M.); ugross@gwdg.de (U.G.); \\ mweig@gwdg.de (M.W.) \\ 2 Regional Center for Biomedical Research, Castilla-La Mancha Science \& Technology Park, \\ University of Castilla-La Mancha, 02008 Albacete, Spain; Jordan.Fernandez@alu.uclm.es \\ 3 Department of Immunology, Microbiology and Parasitology, School of Medicine and Nursing, \\ Universidad del País Vasco (UPV/EHU), 48940 Bilbao, Spain; iker.delapinta@ehu.eus (I.D.-1.-P.); \\ guillermo.quindos@ehu.eus (G.Q.) \\ * Correspondence: piet.degroot@uclm.es (P.W.J.d.G.); obader@gwdg.de (O.B.)
}

Citation: Gómez-Molero, E.;

De-la-Pinta, I.; Fernández-Pereira, J.; Groß, U.; Weig, M.; Quindós, G.; de Groot, P.W.J.; Bader, O. Candida parapsilosis Colony Morphotype Forecasts Biofilm Formation of Clinical Isolates. J. Fungi 2021, 7, 33. https://doi.org/10.3390/jof7010033

Received: 8 December 2020

Accepted: 5 January 2021

Published: 7 January 2021

Publisher's Note: MDPI stays neutral with regard to jurisdictional clai$\mathrm{ms}$ in published maps and institutional affiliations.

Copyright: (C) 2021 by the authors. Licensee MDPI, Basel, Switzerland. This article is an open access article distributed under the terms and conditions of the Creative Commons Attribution (CC BY) license (https:// creativecommons.org/licenses/by/ $4.0 /)$.

\begin{abstract}
Candida parapsilosis is a frequent cause of fungal bloodstream infections, especially in critically ill neonates or immunocompromised patients. Due to the formation of biofilms, the use of indwelling catheters and other medical devices increases the risk of infection and complicates treatment, as cells embedded in biofilms display reduced drug susceptibility. Therefore, biofilm formation may be a significant clinical parameter, guiding downstream therapeutic choices. Here, we phenotypically characterized 120 selected isolates out of a prospective collection of 215 clinical C. parapsilosis isolates, determining biofilm formation, major emerging colony morphotype, and antifungal drug susceptibility of the isolates and their biofilms. In our isolate set, increased biofilm formation capacity was independent of body site of isolation and not predictable using standard or modified European Committee on Antimicrobial Susceptibility Testing (EUCAST) drug susceptibility testing protocols. In contrast, biofilm formation was strongly correlated with the appearance of non-smooth colony morphotypes and invasiveness into agar plates. Our data suggest that the observation of non-smooth colony morphotypes in cultures of $C$. parapsilosis may help as an indicator to consider the initiation of anti-biofilm-active therapy, such as the switch from azole- to echinocandinor polyene-based strategies, especially in case of infections by potent biofilm-forming strains.
\end{abstract}

Keywords: Candida parapsilosis; biofilm; colony morphology; drug susceptibility

\section{Introduction}

Candida parapsilosis was first described as a non-pathogenic yeast with no clinical relevance [1]. However, increased use of medical devices, parenteral nutrition, and nosocomial infections [2] has made C. parapsilosis one of the most critical fungal species causing blood stream infections (BSI) [3], which are of particular relevance in critically ill neonates [4-6] and immunocompromised patients [5,7].

The high infection rate with $C$. parapsilosis among neonates is likely due to the frequent requirement of parenteral nutrition [8] and the concomitant ability of C. parapsilosis to utilize fats and fatty acids as major energy sources [9]. In addition, the immature or compromised immune system may favor infections with this species [10].

Another risk factor for acquiring C. parapsilosis infections is the use of indwelling catheters and other medical devices onto which C. parapsilosis may form biofilms in conjunction with other Candida species or bacteria [4]. Primarily, this is attributed to its capacity to attach to the different materials of which medical devices are made $[5,11,12]$. This feature is highly variable among individual clinical isolates [13]. In C. parapsilosis, the formation 
of biofilms is associated with the ability to form pseudohyphae [14-16] as well as the concomitant change in expression levels of cell wall-localized adhesins such as Als1-7 [17-19] or Rbt1 [20]. Importantly, susceptibility to commonly used azole-based antifungal agents in fungal biofilms on medical devices may be strongly reduced [21,22].

Similar to C. albicans (reviewed in [23]), C. parapsilosis can have different colony morphotypes on diagnostic agar plates (Figure 1). While mixed-morphology culture plates can be the result of infection with multiple strains [24] in diagnostic procedures, also, the morphologic switching of some strains is a well-described phenomenon [25]. In addition to their role in biofilm formation, pseudohyphae formation and adhesin expression are also key to the visual appearance of fungal colonies on solid agars [26-28], which in turn may well be correlated to the capacity to form biofilms in the host, the incorporation of cell wall proteins (CWP), and, consequently, virulence [15].

\section{A}

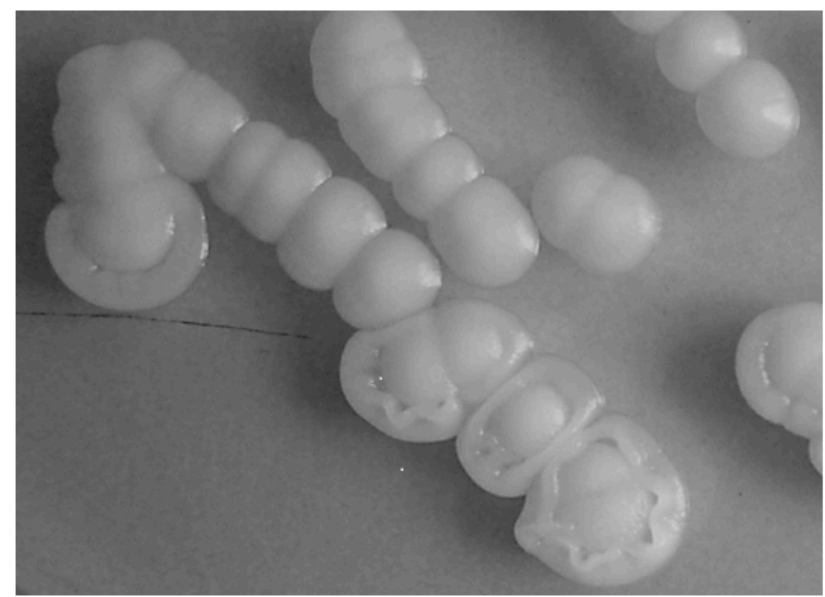

\section{B}
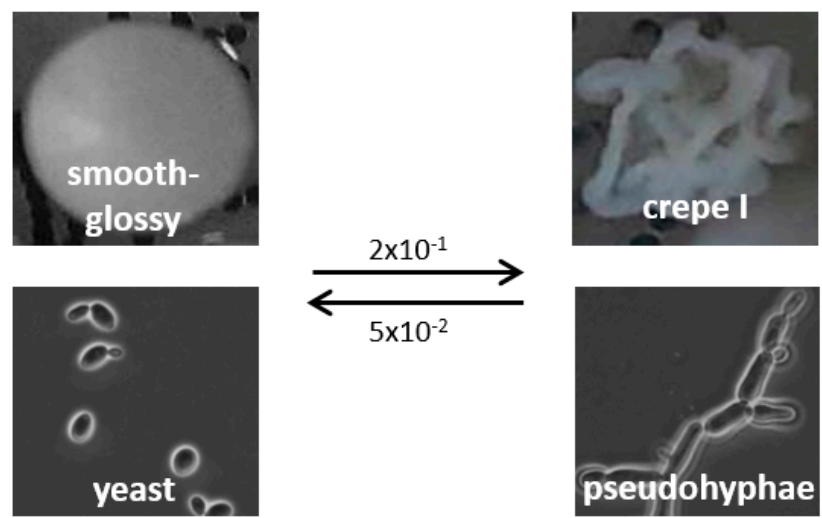

Figure 1. Colony morphotypes formed by C. parapsilosis. (A) Mixed morphotypes observed on a routine diagnostic plate. (B) Cells with distinct morphological colony phenotypes can be subcultured, but some strains (here strain PEU582: smooth-glossy vs. crepe, see below) sometimes undergo switching with strain-dependent frequencies. Smooth colonies are composed mainly of yeast-form cells, whereas non-smooth colonies are composed of pseudohyphal cells or mixtures of both morphologies.

Here, we phenotypically characterized a large collection of clinical C. parapsilosis isolates, including the description of novel intermediate morphotypes. We determined if early colony morphology was a potential predictor of biofilm production and pseudohyphal growth and as such might reveal the need to direct the antifungal therapy against biofilms containing C. parapsilosis. 


\section{Materials and Methods}

\subsection{Clinical Routine Diagnostic and Strain Maintenance}

C. parapsilosis clinical isolates were routinely identified using MALDI-TOF (MALDI Biotyper, Bruker Daltonics, Bremen, Germany) according to the protocol described [29]. Mixed cultures were differentiated on YEPD agar ( $1 \%$ yeast extract, $2 \%$ peptone, $2 \%$ glucose, $2 \%$ agar) supplemented with $5 \mathrm{mg} / \mathrm{mL}$ phloxine $\mathrm{B}$. On this medium, most tested colonies developed a final morphotype within $48 \mathrm{~h}$ of incubation at $30^{\circ} \mathrm{C}$ (Figure 1, Supplementary Figures S1 and S2). Cells from colonies with stable morphotypes were transferred onto Sabouraud dextrose agar (SDA, Oxoid, Munich, Germany), regrown, and stored at $-70{ }^{\circ} \mathrm{C}$ in cryovials (Mast Diagnostica, Reinfeld, Germany) for further analyses.

\subsection{Biofilm Quantitation}

Biofilm quantification assays on polystyrol were performed as described previously [11,30,31], with adaptations to suit $C$. parapsilosis. Briefly, isolates were grown on phloxine B-containing YEPD agar plates. Inoculum was prepared from single colonies grown to stationary phase in YEPD broth at $30{ }^{\circ} \mathrm{C}$ overnight at $220 \mathrm{rpm}$. A cell suspension adjusted to a cell density of McFarland $=2$ was prepared using sterile saline, and $100 \mu \mathrm{L}$ YEPD medium plus $50 \mu \mathrm{L}$ aliquots of the cell suspensions were mixed in 96-well polystyrol microtiter plates (Greiner Bio-one) and incubated for $24 \mathrm{~h}$ at $37^{\circ} \mathrm{C}$. After removal of the medium by aspiration, the attached biofilms were washed once with $200 \mu \mathrm{L}$ of distilled water. Cells were stained for $30 \mathrm{~min}$ in $100 \mu \mathrm{L}$ of $0.1 \%$ aqueous crystal violet (CV). Excess $\mathrm{CV}$ was removed, and the biofilm was washed once with $200 \mu \mathrm{L}$ of distilled water. To release CV from the cells, $200 \mu \mathrm{L}$ of $1 \%$ SDS in $50 \%$ ethanol was added, and the cellular material was resuspended by pipetting. CV absorbance was quantified at $490 \mathrm{~nm}$ using a microtiter plate reader (MRX TC Revelation). Data shown are the average of three independent biological experiments, each including four technical repeats, using reference strain CDC317 as inter-experiment quality control.

\subsection{Antifungal Drug Susceptibility Testing}

Susceptibility testing was performed according to EUCAST e.def 7.3.1 standards [32]. Fluconazole (FLZ), voriconazole (VRZ), posaconazole (POS), and amphotericin B (AMB) substances were purchased from Discovery fine Chemicals Ltd. (Bournemouth, UK), micafungin (MFG) was kindly provided by Astellas, and caspofungin (CAS) was provided by Merck Sharp \& Dohme Corp (MSD). Sequencing of the ERG11 and MRR1 genes was performed as previously described [33].

Preformed biofilms reduction

Cells were pre-grown on Sabouraud dextrose agar (SDA) for $96 \mathrm{~h}$ at $30^{\circ} \mathrm{C}$, and one colony was sub-cultured in $5 \mathrm{~mL}$ of YEPD broth overnight at $37^{\circ} \mathrm{C}$ in an orbital incubator at $200 \mathrm{rpm}$. Cells were harvested by centrifugation and resuspended in Phosphate-buffered saline (PBS). Upon counting cells in a Neubauer chamber, the suspensions were adjusted to $1 \times 10^{6}$ cells $/ \mathrm{mL}$ in both RPMI ( $2 \mathrm{~g} / \mathrm{L}$ glucose, $\mathrm{pH}$ 7) and YEPD (20 g/L glucose, $\mathrm{pH}$ 6.7). One hundred $\mu \mathrm{L}$ of the inoculum was pipetted into each well of a Bioscreen plate (Labsystem, Helsinki, Finland), and the plates were incubated for $24 \mathrm{~h}$ at $37^{\circ} \mathrm{C}$ to allow biofilm formation. Next, planktonic cells were removed, and the plates were washed twice in PBS leaving just the biofilm in the wells. Two-fold serial dilutions of four antifungal drugs were prepared in RPMI or YEPD ranging from 0.25 to $32 \mu \mathrm{g} / \mathrm{mL}$ for POS, VRZ, and MFG, and from 0.0125 to $16 \mu \mathrm{g} / \mathrm{mL}$ for AMB. Subsequently, $100 \mu \mathrm{l}$ of each dilution was added to the corresponding wells with biofilm in triplicate, and the plates were incubated again at $37{ }^{\circ} \mathrm{C}$ for $24 \mathrm{~h}$. Finally, plates were washed twice with PBS, and reduction of the biofilm metabolic activity was determined by measuring the absorbance at $492 \mathrm{~nm}$ with the XTT (2,3-bis-(2-methoxy-4-nitro-5-sulfophenyl)-2H- tetrazolium-5-carboxanilide) colorimetric method [34]. 


\subsection{Morphotype Development and Agar Invasion}

Selected C. parapsilosis isolates were cultured overnight in YEPD liquid media in an orbital shaker at $220 \mathrm{rpm}$ at $30^{\circ} \mathrm{C}$. Cell density was adjusted to $2 \times 10^{2}$ cells $/ \mathrm{mL}$, after which $100 \mu \mathrm{L}$ was plated onto YEPD agar plates and incubated at $30^{\circ} \mathrm{C}$ for ten successive days. Starting after $48 \mathrm{~h}$, the morphotype development of colonies was captured every $24 \mathrm{~h}$ over ten days using a stereoscopic binocular loupe (SZM-1, OPTIKA ${ }^{\circledR}$, Ponteranica, Italy) mounted with a digital camera. Morphotypes and agar invasion were classified according to the references given in Supplementary Figure S1.

For analysis of agar invasion, colonies with different morphotypes were plated onto YEPD agar plates supplemented with $5 \mathrm{mg} / \mathrm{mL}$ of phloxine B [25], and morphotype development was followed as described above. Agar invasion was scored from day 4 onwards by scraping selected colonies with an inoculation loop and eventually washing off the cells under running water on the last day. Agar invasion was classified as low (1), low-medium (2), medium (3), medium-high (4), high (5), and finally as very high (6) when cells could not be removed by rinsing (see scoring reference in Supplementary Figure S1).

\subsection{Statistical Analyses}

For statistical analyses of biofilms and antifungal drug susceptibility, unpaired twosamples Student's $t$-tests were used. All data used were the average of three independent analyses, and $p$ values $<0.05$ were considered statistically significant.

To detect potential correlations between biofilm formation capacity, colony morphotype, and/or agar invasion capacity, regression analyses were performed, and Pearson's correlation coefficient $\mathrm{r}$ was used as a predictor for correlation. All data were analyzed using IMB SPSS 22 statistics software.

\section{Results}

\subsection{Biofilm Formation Capacity Is Independent of Body Site of Isolation}

Over the course of two years, we collected 215 C. parapsilosis clinical isolates from our routine diagnostics (Figure 2). Isolates were classified according to nine different categories depending on the body site of isolation. C. parapsilosis is known to frequently occur in the nape region, reaching up to the ear. Consequently, most isolates stemmed from ear infections; however, a substantial number of isolates from invasive infections at other body sites as well as from indwelling devices such as central venous or urine catheters were included in the study. C. parapsilosis was only infrequently isolated from locations of the GI (2,3-bis-(2-methoxy-4-nitro-5-sulfophenyl)-2H- tetrazolium-5-carboxanilide) tract, the oral cavity, or the skin.

Isolates obtained were systematically screened for their capacity to form biofilms in standard biofilm formation tests in polystyrol microtiter plates. No body site, including those isolate groups obtained from plastic materials, could be identified to be significantly associated with elevated numbers of biofilm-forming isolates ( $p=0.371$, Figure $2 \mathrm{~A})$. When stratified by quantitative measurement values, we observed a near even distribution across the study group; only a tentative cut-off for low biofilm formation capacity was observed at OD (optical density) measurement values of approximately 0.1 (Figure 2B, intersection of black lines). Microscopical imaging of cells in biofilms from some representative isolates confirmed the already established idea that the capacity to form biofilms is correlated with pseudohyphal development (Supplementary Figure S3) [25-28]. 

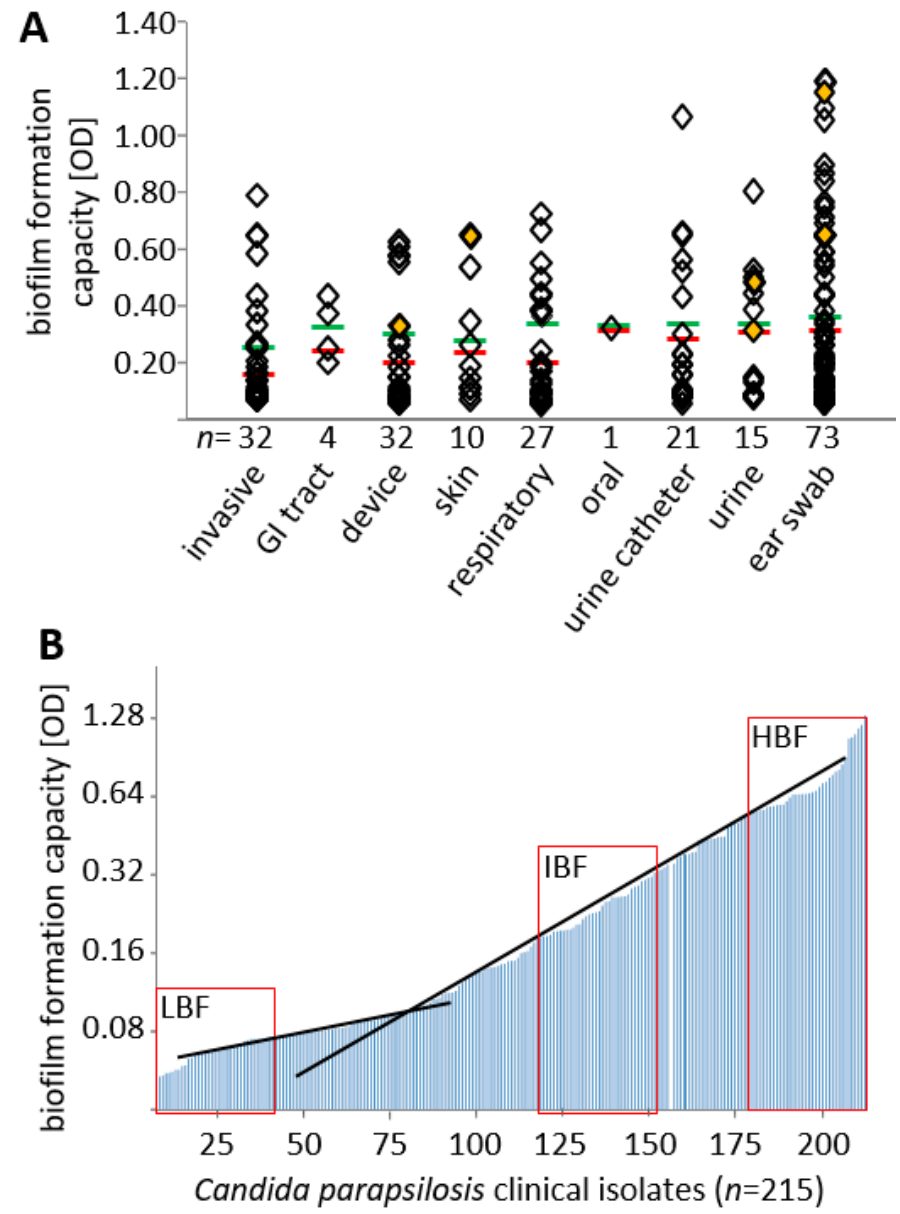

Figure 2. C. parapsilosis collection and selection of isolates for downstream experiments. (A) Distribution of collection isolates stratified according to site of isolation and biofilm production on polystyrol. Category "invasive" includes, e.g., blood culture, biopsies, or intraoperative swabs. Orange diamonds: six isolates used in pre-formed biofilm experiments, see text. Red and green lines: mean and two-fold mean values. (B) Biofilm formation capacity; isolates sorted by value from low to high. Intersection of black lines: approximated cut-off. Red boxes indicate strain selection of representative low (LBF, left box), intermediate (IBF, middle box) and high (HBF, right box) biofilm formers for subsequent experiments.

\subsection{Effect of Biofilm Formation on Antifungal Drug Susceptibility}

In order to estimate the correlation of the lead phenotype (biofilm formation on polystyrol) with drug susceptibility, we selected 40 isolates each of low (LBF), intermediate (IBF), and high (HBF) biofilm formation capacity (Figure 2B, red boxes) from our collection including two non-adherent control strains (CDC317 and ATCC22019). The strains were tested for susceptibility to selected azoles (FLZ, POS, VRZ), echinocandins (CAS, MFG), and one polyene $(\mathrm{AMB})$ after one (young colonies) and eight days (matured colonies) of growth on phloxine $\mathrm{B}$ agar plates.

Four IBF isolates (PEU651, PEU768, PEU941, and PEU950), and reference strain CDC317 showed elevated (minimum inhibitory concentration) MIC (values of 4-16 $\mu \mathrm{g} / \mathrm{mL}$ for FLC. To exclude potential biases through resistance mutations (e.g., Y132F [35]), we sequenced the ERG11 and MRR1 genes in these isolates. A non-synonymous ERG11 point mutation was found only in CDC317, which was heterozygous with respect to the Y132F amino acid exchange. Y132F is known to confer resistance to fluconazole [36,37]. MRR1 only contained non-synonymous SNPs (Single nucleotide polymorphisms) in PEU651. Since we could not exclude a potential influence of these mutations, data for PEU651 
as well as those of the two reference strains were excluded from the drug susceptibility analysis, leaving a total of 117 isolates in three groups of 39 isolates each.

We did not observe large-scale differences in drug susceptibility between experiments undertaken with young or mature colonies except for CAS (LBF $p=0.017$ and HBF $p=0.028$, Figure $3 \mathrm{~A}$ white vs. gray boxes).

A Drug susceptibility stratified by biofilm formation capacity and colony maturation

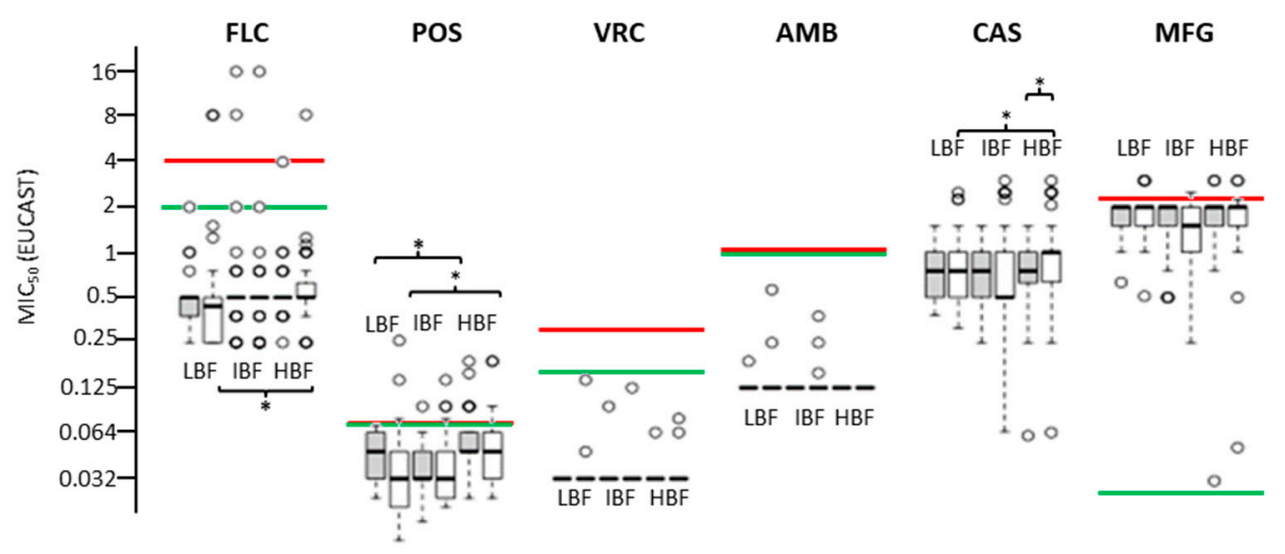

B Effect of antifungal drugs on preformed biofilms grown in RPMI
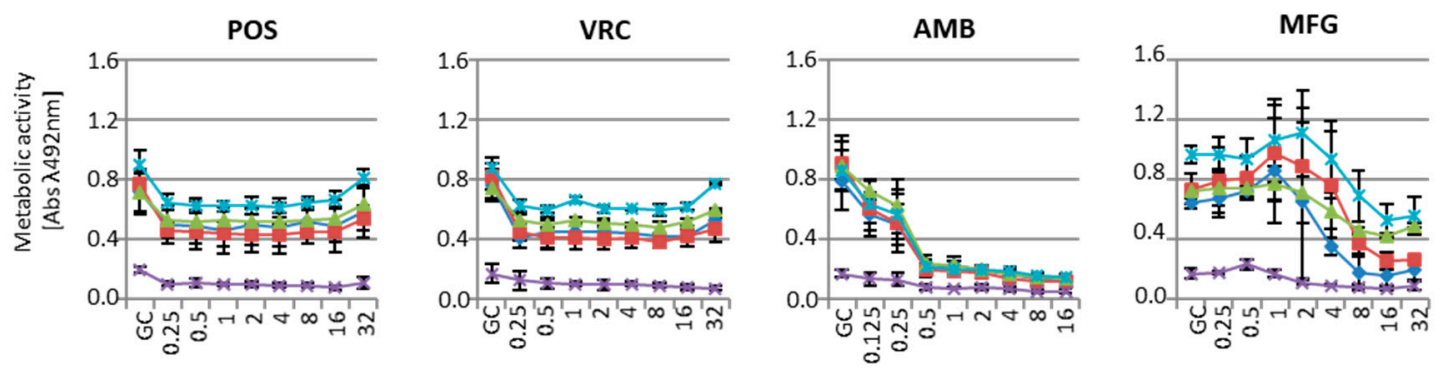

\section{Effect of antifungal drugs on preformed biofilms grown in YEPD}
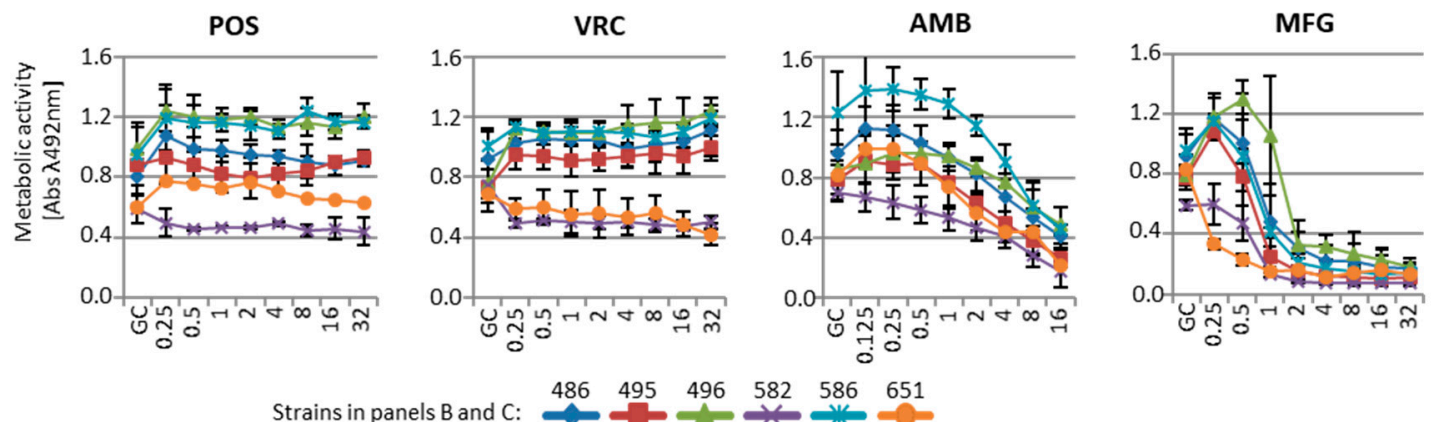

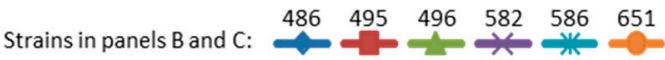

Figure 3. Drug susceptibility. (A) Biofilm formation-phenotype dependent susceptibility testing where inoculum was prepared from cells after 1 day of growth on Sabouraud dextrose agar (SDA) (gray boxes) and after 8 days of growth (white boxes) on the same plates, when colonies had fully developed morphotypes. For each substance tested, the values for 1 and 8-day inoculum are depicted for each group (LBF, IBF, and HBF). Red lines: EUCAST clinical breakpoint (R>); green lines, susceptible cut-off $(\mathrm{S} \leq)$. *: statistical significance $(\mathbf{B}, \mathbf{C})$ Effect of antifungal drugs on cell viability in pre-formed biofilms of selected biofilm-forming isolates tested in (B) RPMI (Roswell Park Memorial Institute )or (C) YEPD(yeast extract peptone dextrose) media.

Although statistically significant differences between $\mathrm{HBF}$ versus IBF or LBF isolate groups were clearly evident for some antifungal drugs (POS: LBF vs. HBF with young 
colonies $p=0.014$, mature colonies $p=0.072$, CAS: LBF vs. HBF with young colonies $p=0.015)$, the observed mean MIC differences did not result in a major change in classification of either susceptible (S) or resistant (R) according to EUCAST breakpoints. Differences in mean susceptibility values were 1-2 log2-fold decreases for VRZ, POS (mature colonies only), CAS, and MFG in the HBF group, as compared to the LBF group. No apparent differences for either FLZ or AMB were seen.

\subsection{Susceptibility of Biofilms to Antifungal Drugs}

Next, for six selected intermediate to high biofilm-forming isolates, we analyzed to which degree pre-formed C. parapsilosis biofilms resisted antifungal drug treatment in two different media, RPMI and YEPD. RPMI is considered the reference medium for antifungal drug susceptibility testing and, as mentioned above, it was also used for MIC determination according to the EUCAST protocol. Likewise, YEPD is a glucose-rich medium that is widely used in assays with yeasts due to the large amount of peptone and dextrose extremely necessary for yeast growth and biofilm formation. The ability to form biofilms was evaluated using this culture medium. Since both media are widely used in the literature, we decided to test the drug susceptibility of preformed biofilms in both of them, observing that some strains are more prone to form biofilms in one media and not in the other, as well as behaving differently when interacting with antifungal drugs. More specifically, one of the six isolates (PEU651) was not able to form biofilm in RPMI (Figure 3B), whereas another (PEU582) grew only at reduced rates. Both isolates also showed a reduction in biofilm development in YEPD (Figure 3C) but were kept in these assays as the results were qualitatively in agreement with the other strains used.

Antifungal drugs had different quantitative effects when the assay was carried out in RPMI (Figure 3B) or in YEPD (Figure 3C). In YEPD, sub-inhibitory drug concentrations caused increases in metabolic activity, as measured by XTT reduction. This may be a stress-response effect countering drugs at these levels, and it was considered an artifact for the purpose of this study. Higher concentrations of azoles (POS, VRZ) reduced biofilm metabolic activity by only $30-50 \%$ as compared to the drug-free control. There was no azole drug concentration in the measurement range (up to $32 \mu \mathrm{g} / \mathrm{mL}$ ) that led to a full reduction in biofilm metabolic activity (all $p>0.05$ ). In contrast, both MFG and AMB did achieve a strong reduction of metabolic activity, although under different conditions: in RPMI, an AMB concentration of $0.5 \mu \mathrm{g} / \mathrm{mL}$ was sufficient for $70 \%$ reduction, while $16 \mu \mathrm{g} / \mathrm{mL}$ were required in YEPD. For MFG, this was the opposite: in YEPD, a clear effect was seen at $2 \mu \mathrm{g} / \mathrm{mL}$ with only residual metabolic activity apparent up to the upper assay boundaries $(32 \mu \mathrm{g} / \mathrm{mL})$.

\subsection{Biofilm Formation Capacity on Polystyrol Correlates with Colony Morphotype and Agar Invasiveness}

On culture plates, individual C. parapsilosis isolates showed specific, stable morphotypes. Only a minority of isolates $(18 \%)$ were also able to switch between such morphotypes upon re-plating (Figure 1 and scoring reference shown in Supplementary Figure S1).

In a preliminary analysis on a selected subset (Supplementary Figure S2), non-smooth colony morphologies were already apparent at the start of the observation period $(20 \%)$ and reliably appeared after $72 \mathrm{~h}$ of growth. Across the entire collection, agar invasion (Supplementary Figure S1A) and colony morphotype (Supplementary Figures S1B and S2) were therefore scored over a course of four to ten days (Figure 4). Most LBF isolates (90\%) showed smooth morphotypes, and only a small proportion (10\%), for instance PEU944, developed wrinkled or crepe phenotypes. On day 10, about $20 \%$ had developed nonsmooth morphotypes as their major morphology (Figure 4A). With increasing biofilm formation capacity, also the frequency of non-smooth colony morphotypes increased. Of the IBF isolates, $20 \%$ had developed non-smooth morphotypes at day 4 , and $55 \%$ had developed non-smooth morphotypes on day 10. HBF isolates mainly, but not exclusively, produced non-smooth phenotypes (66\% on day $4,83 \%$ on day 10 ), which in most cases were already distinguishable at day 2 . Some isolates presented two independent stable 
morphotypes (e.g., PEU525: non-smooth (cr) and smooth (s)), which were distinguishable from day 2 until day 10. Along with the increased formation of non-smooth colony morphotypes in IBF and HBF strains $(r=0.832, p<0.001)$, also agar invasiveness increased from day 4 to day $10\left(\mathrm{r}=0.969,{ }^{* * *} p<0.001\right.$ (Figure $4 \mathrm{~B}$, Table 1 ).

A morphotype development
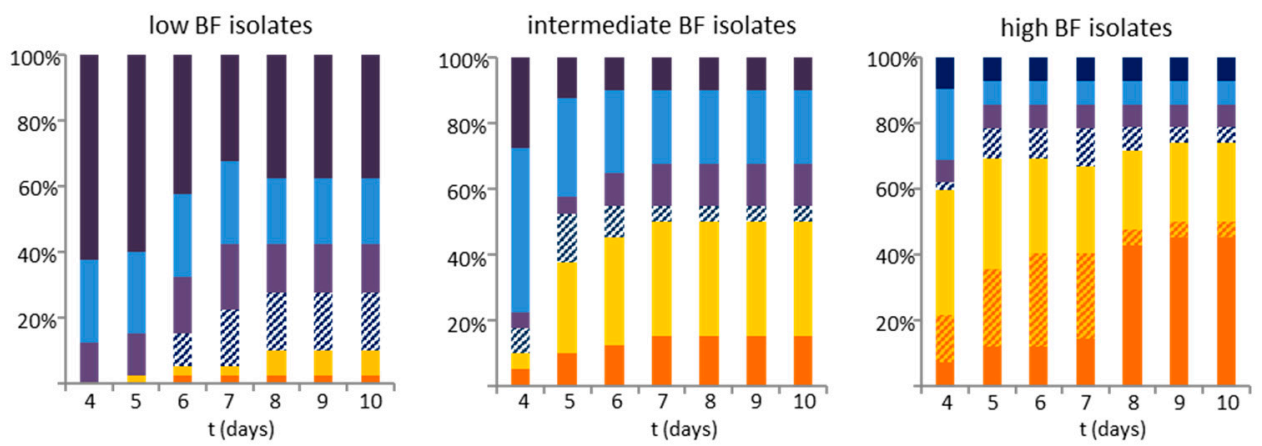

amooth-glossy

amooth-matte

- smooth-concentric

Z other

Z. mixed snowball/wrinkled/crepe

wrinkled

crepe I/II

\section{B agar invasion}

low BF isolates

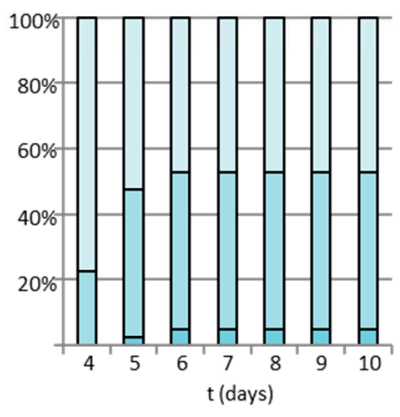

$\square$ low

$\square$ low-medium intermediate BF isolates

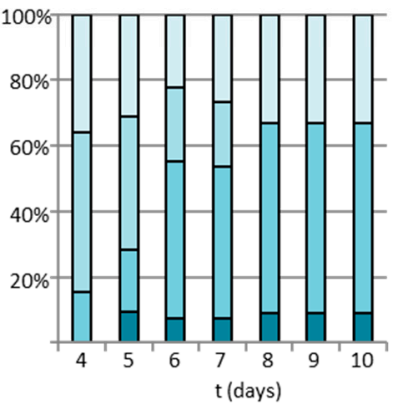

$\square$ medium

medium-high

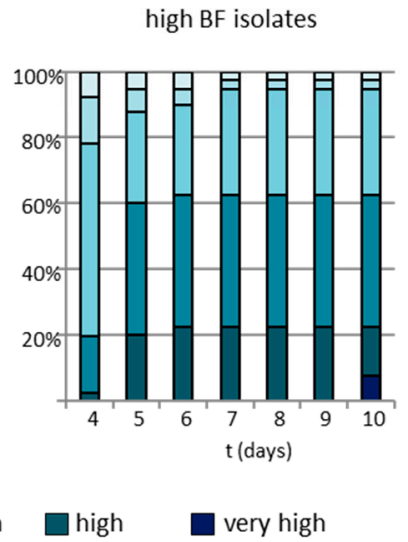

Figure 4. Emergence of colony morphotype over time. (A) Development of colony morphotype and (B) agar invasiveness scoring the same plates consecutively from 4 days to 10 days after inoculation. Isolates with low biofilm formation capacity (left panels), intermediate biofilm formation capacity (middle panels), and high biofilm formation capacity (right panels) were scored for the most frequent colony morphotype visible. Of note, HBF isolates rated "smooth" still developed minor frequencies of non-smooth colonies. See Supplementary Figure S1 for scoring references.

Table 1. Agar invasiveness and colony morphology.

\begin{tabular}{|c|c|c|c|c|c|c|c|}
\hline \multirow{2}{*}{ Morphology ${ }^{a}$} & \multirow{2}{*}{$n$} & \multicolumn{6}{|c|}{ Agar Invasion ${ }^{a}$} \\
\hline & & Low & Low-Medium & Medium & Medium-High & High & Very High \\
\hline smooth & 59 & $34 \%$ & $27 \%$ & $5 \%$ & $32 \%$ & $2 \%$ & $0 \%$ \\
\hline wrinkled & 22 & $5 \%$ & $9 \%$ & $23 \%$ & $50 \%$ & $9 \%$ & $5 \%$ \\
\hline mixed/infrequent & 16 & $0 \%$ & $6 \%$ & $6 \%$ & $63 \%$ & $19 \%$ & $6 \%$ \\
\hline crepe I and II & 25 & $4 \%$ & $4 \%$ & $0 \%$ & $36 \%$ & $28 \%$ & $28 \%$ \\
\hline
\end{tabular}

${ }^{a}$ see Supplementary Figure S1 for classification of agar invasion and morphotypes.

\section{Discussion}

C. parapsilosis is frequently found as a cause of pathologies due to biofilm formation on medical devices in long-term hospitalized patients suffering from endocarditis, peritonitis, 
arthritis, or general sepsis [22,38-40]. We hypothesized that the capacity to form biofilm might be related to the origin of the clinical specimen, that is, infections at different body sites or fungus growing on medical devices such as indwelling catheters. However, when the 215 clinical isolates in our collection were scored for their biofilm-forming capacity on rich medium (YEPD), a strong inducer of biofilms in C. parapsilosis [41], no clear distribution of low (LBF) versus high (HBF) biofilm formation depending on the site of isolation was detected. Nevertheless, a high percentage of catheter-associated isolates belonged to the IBF and HBF groups, which is consistent with the notion that $C$. parapsilosis infections often start from infected indwelling devices [42,43].

Then, we raised the question of whether there might be a possible link between the biofilm-forming capacity of clinical isolates and their drug susceptibility [21,22], which could be useful for decision making about treatment strategies in the clinic. However, tests with the three groups of isolates (LBF, IBF, and HBF), reflecting a wide range-from negligible to high quantities of biomass-of biofilm-formation capacity on polystyrol, and six commonly used azole-, echinocandin-, and polyene antifungal agents did not reveal any such correlation. Observed MIC values were similar to those reported previously by others [44-47], and also, no remarkable differences were observed between inocula prepared from young or matured cells (as found in biofilms). Therefore, we conclude that the drug susceptibility data obtained with the standard EUCAST protocol do not seem to generate predictive information toward the biofilm-formation capacity of clinical isolates.

Nevertheless, fungal cells embedded within biofilms, including those formed by $C$. parapsilosis, are considered to be less susceptible to antifungal compounds [21,22]. This notion was confirmed here by studying the antifungal drug susceptibility of six biofilmforming strains embedded in preformed biofilms, which showed significantly reduced sensitivity to azoles. This experiment was executed in both YEPD (high glucose) and RPMI (lower glucose) medium. As expected [41], biofilm formation in YEPD was higher than in RPMI, and media-dependent differences in echinocandin and polyene sensitivity were also noted. These observations support earlier reported overall quantitative dependences of biofilm formation and drug susceptibility on glucose levels in the media $[41,48,49]$.

Another important aspect of our study was the question of whether C. parapsilosis colony morphotypes might perhaps serve to forecast the biofilm-forming capacity of clinical isolates. We hypothesized that high biofilm formers would show more non-smooth morphotypes and pseudohyphae than poor biofilm formers and have an increased tendency to invade agar [50]. When following colony morphotype development in the three isolate groups (LBF, IBF, and HBF) over a course of ten days, we indeed observed a strong correlation of the HBF group with non-smooth colony morphotypes. In contrast, the appearance of non-smooth colonies occurred only in a minority of the isolates in the LBF group. As surface adherence represents the first step in biofilm formation, our data are supported by studies showing that non-smooth colonies are generally more adherent to plastic than smooth colonies [51].

Interestingly, in most cases, non-smooth morphotypes could already be observed within $48 \mathrm{~h}$ of growth, and only little change was observed after $96 \mathrm{~h}$, indicating that prolonged incubation beyond this time point is not needed for morphotype determination. In addition, all the morphotypes appeared stable, as they were reproduced upon repeating the experiment, which is consistent with the idea that switching is not a common or frequent event. Finally, biofilm-forming capacity and the appearance of non-smooth morphotypes and pseudohyphae were positively correlated to agar invasion. However, a large proportion of smooth colony types also displayed medium-strength agar invasion, indicating pseudohyphae formation at least at the base of the colony [52,53].

In summary, our experiments show that there is a strong correlation between colony morphotype and biofilm formation capacity in isolates from clinical samples and that this is not reflected in the results from standard antifungal drug susceptibility testing. Our data are the first to indicate that the observation of non-smooth colony morphotypes of C. parapsilosis may help to consider the initiation of anti-biofilm-active therapy. This may 
include antifungal lock therapy and shifting treatment from azole-based to echinocandinor polyene-based strategies to eliminate biofilms from catheters [39]. However, due to the inherent ability of some strains to switch between morphotypes [25-28,54], the absence of such colonies should not be taken as an absolute indicator that biofilms do not exist in the patient.

Supplementary Materials: The following are available online at https:/ / www.mdpi.com/2309-6 08X/7/1/33/s1, Supplementary Figure S1. Morphological classification of C. parapsilosis colony morphotypes. (A) Semi-quantitative classification of agar invasion on phloxine B-containing SDA. (B) Colony morphotypes observed in our isolate collection. In picture pairs, left pictures represent colony morphotype after $10 \mathrm{~d}$ incubation, right pictures show agar imprint left on phloxine B agar plates after flushing off colonies with running water. Scale bars $=0.25 \mathrm{~cm}$; Supplementary Figure S2. Colony morphotype development during a ten-day time-lapse experiment. Morphotype development of colonies was followed during ten days of growth on YEPD agar at $30^{\circ} \mathrm{C}$. (A) Five selected low biofilm-forming (LBF) clinical isolates, (B) five intermediate biofilm-forming (IBF) isolates, and (C) five high-biofilm-forming (HBF) isolates. d, derby; cn, concentric; cr, crater; s, smooth; wr, wrinkled; Supplementary Figure S3. Morphology of C. parapsilosis cells in biofilms onto polystyrol. Representative strains with low (LBF, row 1), intermediate (IBF, row2), and high (HBF, rows 3 and 4) biofilm formation capacity are shown. Biofilms were let to develop for $24 \mathrm{~h}$ in YEPD as described in materials and methods. Unbound cells were removed by washing with PBS. Remaining biofilm cells were observed with a Leica DM1000 microscope mounted with a HC PL 100×/1.32 objective and MC170 HD digital camera.

Author Contributions: Conceptualization, E.G.-M., P.W.J.d.G. and O.B.; Formal analysis, E.G.-M., I.D.-1.-P., J.F.-P. and P.W.J.d.G.; Funding acquisition, U.G., G.Q., P.W.J.d.G. and O.B.; Investigation, E.G.-M., I.D.-1.-P. and J.F.-P.; Methodology, E.G.-M., M.W. and G.Q.; Project administration, O.B.; Resources, U.G.and M.W.; Supervision, G.Q., P.W.J.d.G. and O.B.; Writing-original draft, E.G.-M., M.W., P.W.J.d.G. and O.B.; Writing-review \& editing, G.Q. and O.B. All authors have read and agreed to the published version of the manuscript.

Funding: This work was funded in part by grants or scholarships from the ZabaldUz program (Universidad del País Vasco/Euskal Herriko Unibertsitatea) to IDIP, the Consejería de Educación, Universidades e Investigación (GIC15/78 IT-990-16) of Gobierno Vasco-Eusko Jaurlaritza to GQ, the Ministerio de Economía y Competitividad (grants SAF2013-47570-P and SAF2017-86188-P, the latter co-financed by FEDER) of the Spanish government to P.G. and G.Q., and the FP7-PEOPLE-2013ITN-Marie-Curie Action: "Initial Training Networks": Molecular Mechanisms of Human Fungal Pathogen Host Interaction, ImResFun, MC-ITN-606786, to O.B. and U.G.

Institutional Review Board Statement: Not applicable.

Informed Consent Statement: Not applicable.

Data Availability Statement: The data presented in this study are available upon reasonable request from the corresponding author.

Acknowledgments: Agnieszka Goretzki and Yvonne Laukat are thanked for performing susceptibility testing.

Conflicts of Interest: The authors declare no conflict of interest.

\section{References}

1. Weems, J.J., Jr. Candida parapsilosis: Epidemiology, pathogenicity, clinical manifestations, and antimicrobial susceptibility. Clin. Infect. Dis. 1992, 14, 756-766. [CrossRef] [PubMed]

2. Krcmery, V.; Barnes, A.J. Non-albicans Candida spp. causing fungaemia: Pathogenicity and antifungal resistance. J. Hosp. Infect. 2002, 50, 243-260. [CrossRef] [PubMed]

3. Pfaller, M.A.; Diekema, D.J. Role of sentinel surveillance of candidemia: Trends in species distribution and antifungal susceptibility. J. Clin. Microbiol. 2002, 40, 3551-3557. [CrossRef] [PubMed]

4. Pammi, M.; Holland, L.; Butler, G.; Gacser, A.; Bliss, J.M. Candida parapsilosis is a significant neonatal pathogen: A systematic review and meta-analysis. Pediatr. Infect. Dis. J. 2013, 32, e206-e216. [CrossRef]

5. Trofa, D.; Gacser, A.; Nosanchuk, J.D. Candida parapsilosis, an emerging fungal pathogen. Clin. Microbiol. Rev. 2008, 21, 606-625. [CrossRef] 
6. Lindberg, E.; Hammarstrom, H.; Ataollahy, N.; Kondori, N. Species distribution and antifungal drug susceptibilities of yeasts isolated from the blood samples of patients with candidemia. Sci. Rep. 2019, 9, 3838. [CrossRef]

7. Toth, R.; Nosek, J.; Mora-Montes, H.M.; Gabaldon, T.; Bliss, J.M.; Nosanchuk, J.D.; Turner, S.A.; Butler, G.; Vagvolgyi, C.; Gacser, A. Candida parapsilosis: From Genes to the Bedside. Clin. Microbiol. Rev. 2019, 32. [CrossRef]

8. Lupetti, A.; Tavanti, A.; Davini, P.; Ghelardi, E.; Corsini, V.; Merusi, I.; Boldrini, A.; Campa, M.; Senesi, S. Horizontal transmission of Candida parapsilosis candidemia in a neonatal intensive care unit. J. Clin. Microbiol. 2002, 40, 2363-2369. [CrossRef]

9. Gacser, A.; Trofa, D.; Schafer, W.; Nosanchuk, J.D. Targeted gene deletion in Candida parapsilosis demonstrates the role of secreted lipase in virulence. J. Clin. Investig. 2007, 117, 3049-3058. [CrossRef]

10. Linden, J.R.; De Paepe, M.E.; Laforce-Nesbitt, S.S.; Bliss, J.M. Galectin-3 plays an important role in protection against disseminated candidiasis. Med. Mycol. 2013, 51, 641-651. [CrossRef]

11. Kuhn, D.M.; Chandra, J.; Mukherjee, P.K.; Ghannoum, M.A. Comparison of biofilms formed by Candida albicans and Candida parapsilosis on bioprosthetic surfaces. Infect. Immun. 2002, 70, 878-888. [CrossRef] [PubMed]

12. Neji, S.; Hadrich, I.; Trabelsi, H.; Abbes, S.; Cheikhrouhou, F.; Sellami, H.; Makni, F.; Ayadi, A. Virulence factors, antifungal susceptibility and molecular mechanisms of azole resistance among Candida parapsilosis complex isolates recovered from clinical specimens. J. Biomed. Sci. 2017, 24, 67. [CrossRef] [PubMed]

13. Silva, S.; Henriques, M.; Martins, A.; Oliveira, R.; Williams, D.; Azeredo, J. Biofilms of non-Candida albicans Candida species: Quantification, structure and matrix composition. Med. Mycol. 2009, 47, 681-689. [CrossRef] [PubMed]

14. Lattif, A.A.; Mukherjee, P.K.; Chandra, J.; Swindell, K.; Lockhart, S.R.; Diekema, D.J.; Pfaller, M.A.; Ghannoum, M.A. Characterization of biofilms formed by Candida parapsilosis, C. metapsilosis, and C. orthopsilosis. Int. J. Med. Microbiol. 2010, 300, 265-270. [CrossRef] [PubMed]

15. Pannanusorn, S.; Fernandez, V.; Romling, U. Prevalence of biofilm formation in clinical isolates of Candida species causing bloodstream infection. Mycoses 2013, 56, 264-272. [CrossRef] [PubMed]

16. Kozik, A.; Karkowska-Kuleta, J.; Zajac, D.; Bochenska, O.; Kedracka-Krok, S.; Jankowska, U.; Rapala-Kozik, M. Fibronectin-, vitronectin- and laminin-binding proteins at the cell walls of Candida parapsilosis and Candida tropicalis pathogenic yeasts. BMC Microbiol. 2015, 15, 197. [CrossRef]

17. Butler, G.; Rasmussen, M.D.; Lin, M.F.; Santos, M.A.; Sakthikumar, S.; Munro, C.A.; Rheinbay, E.; Grabherr, M.; Forche, A.; Reedy, J.L.; et al. Evolution of pathogenicity and sexual reproduction in eight Candida genomes. Nature 2009, 459, 657-662. [CrossRef]

18. Pryszcz, L.P.; Nemeth, T.; Gacser, A.; Gabaldon, T. Unexpected genomic variability in clinical and environmental strains of the pathogenic yeast Candida parapsilosis. Genome Biol. Evol. 2013, 5, 2382-2392. [CrossRef]

19. Neale, M.N.; Glass, K.A.; Longley, S.J.; Kim, D.J.; Laforce-Nesbitt, S.S.; Wortzel, J.D.; Shaw, S.K.; Bliss, J.M. Role of the Inducible Adhesin CpAls7 in Binding of Candida parapsilosis to the Extracellular Matrix under Fluid Shear. Infect. Immun. 2018, 86. [CrossRef]

20. Rossignol, T.; Ding, C.; Guida, A.; d'Enfert, C.; Higgins, D.G.; Butler, G. Correlation between biofilm formation and the hypoxic response in Candida parapsilosis. Eukaryot. Cell 2009, 8, 550-559. [CrossRef]

21. Katragkou, A.; Chatzimoschou, A.; Simitsopoulou, M.; Dalakiouridou, M.; Diza-Mataftsi, E.; Tsantali, C.; Roilides, E. Differential activities of newer antifungal agents against Candida albicans and Candida parapsilosis biofilms. Antimicrob. Agents Chemother. 2008, 52, 357-360. [CrossRef] [PubMed]

22. Soldini, S.; Posteraro, B.; Vella, A.; De Carolis, E.; Borghi, E.; Falleni, M.; Losito, A.R.; Maiuro, G.; Trecarichi, E.M.; Sanguinetti, M.; et al. Microbiologic and clinical characteristics of biofilm-forming Candida parapsilosis isolates associated with fungaemia and their impact on mortality. Clin. Microbiol. Infect. 2018, 24, 771-777. [CrossRef] [PubMed]

23. Soll, D.R. The role of phenotypic switching in the basic biology and pathogenesis of Candida albicans. J. Oral Microbiol. 2014, 6 . [CrossRef] [PubMed]

24. Gómez-Molero, E.; Willis, J.; Dudakova, A.; Gacser, A.; Weig, M.; Groß, U.; Gabaldón, T.; Bader, O. Phenotypic variability in a coinfection with three independent C. parapsilosis lineages. Front. Microbiol. 2020, 11. [CrossRef] [PubMed]

25. Laffey, S.F.; Butler, G. Phenotype switching affects biofilm formation by Candida parapsilosis. Microbiology 2005, 151, 1073-1081. [CrossRef] [PubMed]

26. Lott, T.J.; Kuykendall, R.J.; Welbel, S.F.; Pramanik, A.; Lasker, B.A. Genomic heterogeneity in the yeast Candida parapsilosis. Curr. Genet. 1993, 23, 463-467. [CrossRef] [PubMed]

27. Enger, L.; Joly, S.; Pujol, C.; Simonson, P.; Pfaller, M.; Soll, D.R. Cloning and characterization of a complex DNA fingerprinting probe for Candida parapsilosis. J. Clin. Microbiol. 2001, 39, 658-669. [CrossRef]

28. Nosek, J.; Holesova, Z.; Kosa, P.; Gacser, A.; Tomaska, L. Biology and genetics of the pathogenic yeast Candida parapsilosis. Curr. Genet. 2009, 55, 497-509. [CrossRef]

29. Bernhard, M.; Weig, M.; Zautner, A.E.; Gross, U.; Bader, O. Yeast on-target lysis (YOTL), a procedure for making auxiliary mass spectrum data sets for clinical routine identification of yeasts. J. Clin. Microbiol. 2014, 52, 4163-4167. [CrossRef]

30. Chandra, J.; Kuhn, D.M.; Mukherjee, P.K.; Hoyer, L.L.; McCormick, T.; Ghannoum, M.A. Biofilm formation by the fungal pathogen Candida albicans: Development, architecture, and drug resistance. J. Bacteriol. 2001, 183, 5385-5394. [CrossRef] [PubMed]

31. Gómez-Molero, E.; de Boer, A.D.; Dekker, H.L.; Moreno-Martínez, A.; Kraneveld, E.A.; Ichsan Chauhan, N.; Weig, M.; de Soet, J.J.; de Koster, C.G.; Bader, O.; et al. Proteomic analysis of hyperadhesive Candida glabrata clinical isolates reveals a core wall proteome and differential incorporation of adhesins. FEMS Yeast Res. 2015, 15, fov098. [CrossRef] [PubMed] 
32. EUCAST. Available online: http://www.eucast.org/fileadmin/src/media/PDFs/EUCAST_files/AFST/Files/EUCAST_E_Def_ 7_3_1_Yeast_testing_definitive.pdf (accessed on 16 April 2019).

33. Grossman, N.T.; Pham, C.D.; Cleveland, A.A.; Lockhart, S.R. Molecular mechanisms of fluconazole resistance in Candida parapsilosis isolates from a U.S. surveillance system. Antimicrob. Agents Chemother. 2015, 59, 1030-1037. [CrossRef]

34. Ramage, G.; Vande Walle, K.; Wickes, B.L.; Lopez-Ribot, J.L. Standardized method for in vitro antifungal susceptibility testing of Candida albicans biofilms. Antimicrob. Agents Chemother. 2001, 45, 2475-2479. [CrossRef] [PubMed]

35. Arastehfar, A.; Daneshnia, F.; Hilmioglu-Polat, S.; Fang, W.; Yasar, M.; Polat, F.; Yesim Metin, D.; Rigole, P.; Coenye, T.; Ilkit, M.; et al. First report of candidemia clonal outbreak caused by emerging fluconazole-resistant Candida parapsilosis isolates harboring Y132F and/or Y132F+K143R in Turkey. Antimicrob. Agents Chemother. 2020. [CrossRef] [PubMed]

36. Souza, A.C.; Fuchs, B.B.; Pinhati, H.M.; Siqueira, R.A.; Hagen, F.; Meis, J.F.; Mylonakis, E.; Colombo, A.L. Candida parapsilosis Resistance to Fluconazole: Molecular Mechanisms and In Vivo Impact in Infected Galleria mellonella Larvae. Antimicrob. Agents Chemother. 2015, 59, 6581-6587. [CrossRef] [PubMed]

37. Magobo, R.E.; Lockhart, S.R.; Govender, N.P. Fluconazole-resistant Candida parapsilosis strains with a Y132F substitution in the ERG11 gene causing invasive infections in a neonatal unit, South Africa. Mycoses 2020, 63, 471-477. [CrossRef]

38. Van Asbeck, E.C.; Clemons, K.V.; Stevens, D.A. Candida parapsilosis: A review of its epidemiology, pathogenesis, clinical aspects, typing and antimicrobial susceptibility. Crit. Rev. Microbiol. 2009, 35, 283-309. [CrossRef]

39. Imbert, C.; Rammaert, B. What Could Be the Role of Antifungal Lock-Solutions? From Bench to Bedside. Pathogens 2018, 7, 6. [CrossRef]

40. Borges, K.R.A.; Pimentel, I.V.; Lucena, L.; Silva, M.; Monteiro, S.G.; Monteiro, C.A.; Nascimento, M.; Bezerra, G.F.B. Adhesion and biofilm formation of Candida parapsilosis isolated from vaginal secretions to copper intrauterine devices. Rev. Inst. Med. Trop. Sao Paulo 2018, 60, e59. [CrossRef]

41. Tan, Y.; Leonhard, M.; Ma, S.; Schneider-Stickler, B. Influence of culture conditions for clinically isolated non-albicans Candida biofilm formation. J. Microbiol. Methods 2016, 130, 123-128. [CrossRef]

42. Silva, S.; Negri, M.; Henriques, M.; Oliveira, R.; Williams, D.W.; Azeredo, J. Candida glabrata, Candida parapsilosis and Candida tropicalis: Biology, epidemiology, pathogenicity and antifungal resistance. FEMS Microbiol. Rev. 2012, 36, 288-305. [CrossRef] [PubMed]

43. Thomaz, D.Y.; de Almeida, J.N., Jr.; Lima, G.M.E.; Nunes, M.O.; Camargo, C.H.; Grenfell, R.C.; Benard, G.; Del Negro, G.M.B. An Azole-Resistant Candida parapsilosis Outbreak: Clonal Persistence in the Intensive Care Unit of a Brazilian Teaching Hospital. Front. Microbiol. 2018, 9, 2997. [CrossRef] [PubMed]

44. Melo, A.S.; Bizerra, F.C.; Freymuller, E.; Arthington-Skaggs, B.A.; Colombo, A.L. Biofilm production and evaluation of antifungal susceptibility amongst clinical Candida spp. isolates, including strains of the Candida parapsilosis complex. Med. Mycol. 2011, 49, 253-262. [CrossRef] [PubMed]

45. Espinel-Ingroff, A.; Barchiesi, F.; Cuenca-Estrella, M.; Pfaller, M.A.; Rinaldi, M.; Rodriguez-Tudela, J.L.; Verweij, P.E. International and multicenter comparison of EUCAST and CLSI M27-A2 broth microdilution methods for testing susceptibilities of Candida spp. to fluconazole, itraconazole, posaconazole, and voriconazole. J. Clin. Microbiol. 2005, 43, 3884-3889. [CrossRef] [PubMed]

46. Modiri, M.; Hashemi, S.J.; Ghazvin, I.R.; Khodavaisy, S.; Ahmadi, A.; Ghaffari, M.; Rezaie, S. Antifungal susceptibility pattern and biofilm-related genes expression in planktonic and biofilm cells of Candida parapsilosis species complex. Curr. Med. Mycol. 2019, 5, 35-42. [CrossRef]

47. Khodavaisy, S.; Badali, H.; Meis, J.F.; Modiri, M.; Mahmoudi, S.; Abtahi, H.; Salehi, M.; Dehghan Manshadi, S.A.; Aala, F.; Agha Kuchak Afshari, S.; et al. Comparative in vitro activities of seven antifungal drugs against clinical isolates of Candida parapsilosis complex. J. Mycol. Med. 2020, 30, 100968. [CrossRef]

48. Rodriguez-Tudela, J.L.; Gomez-Lopez, A.; Arendrup, M.C.; Garcia-Effron, G.; Perlin, D.S.; Lass-Florl, C.; Cuenca-Estrella, M. Comparison of caspofungin MICs by means of EUCAST method EDef 7.1 using two different concentrations of glucose. Antimicrob. Agents Chemother. 2010, 54, 3056-3057. [CrossRef]

49. Santos, F.; Leite-Andrade, M.C.; Brandao, I.S.; Alves, A.; Buonafina, M.D.S.; Nunes, M.; Araujo-Neto, L.N.; Freitas, M.A.; Brayner, F.A.; Alves, L.C.; et al. Anti-biofilm effect by the combined action of fluconazole and acetylsalicylic acid against species of Candida parapsilosis complex. Infect. Genet. Evol. 2020, 84, 104378. [CrossRef]

50. Pannanusorn, S.; Ramirez-Zavala, B.; Lunsdorf, H.; Agerberth, B.; Morschhauser, J.; Romling, U. Characterization of biofilm formation and the role of BCR1 in clinical isolates of Candida parapsilosis. Eukaryot. Cell 2014, 13, 438-451. [CrossRef]

51. De Bernardis, F.; Mondello, F.; San Millan, R.; Ponton, J.; Cassone, A. Biotyping and virulence properties of skin isolates of Candida parapsilosis. J. Clin. Microbiol. 1999, 37, 3481-3486. [CrossRef]

52. Rupp, S.; Summers, E.; Lo, H.J.; Madhani, H.; Fink, G. MAP kinase and cAMP filamentation signaling pathways converge on the unusually large promoter of the yeast FLO11 gene. EMBO J. 1999, 18, 1257-1269. [CrossRef] [PubMed]

53. Chakraborty, T.; Toth, Z.; Toth, R.; Vagvolgyi, C.; Gacser, A. Iron Metabolism, Pseudohypha Production, and Biofilm Formation through a Multicopper Oxidase in the Human-Pathogenic Fungus Candida parapsilosis. mSphere 2020, 5. [CrossRef] [PubMed]

54. Cassone, A.; De Bernardis, F.; Pontieri, E.; Carruba, G.; Girmenia, C.; Martino, P.; Fernandez-Rodriguez, M.; Quindos, G.; Ponton, J. Biotype diversity of Candida parapsilosis and its relationship to the clinical source and experimental pathogenicity. J. Infect. Dis. 1995, 171, 967-975. [CrossRef] [PubMed] 